\title{
Development and evaluation of canine reference genes for accurate quantification of gene expression
}

\author{
Bas Brinkhof*, Bart Spee, Jan Rothuizen, Louis C. Penning \\ Department of Clinical Sciences of Companion Animals, Faculty of Veterinary Medicine, Utrecht University, 3508 TD Utrecht, The Netherlands
}

Received 12 January 2006

Available online 15 June 2006

\begin{abstract}
In determining relative gene expression by quantitative measurements of mRNA levels using real-time quantitative PCR, internal standards such as reference genes are essential. Large-scale studies evaluating (candidate) reference genes for veterinary research have not been conducted as thoroughly as for human research, although they are equally important. Our goal was to design and evaluate a genome-wide panel of reference genes from different functional classes. First, primers were optimized using mRNA from canine cell lines and from 30 tissues of one dog as template and SYBR green as fluorescent probe. Second, the expression variation and stability of a gene within one specific tissue were determined. Prostate, kidney, mammary gland, left ventricle, and liver tissues from five to nine dogs of different breeds, sexes, ages, body weights, and disease status were used. Averaging relative stabilities over these tissues revealed the usefulness of individual genes as reference genes. Furthermore, according to expression variation of a reference gene within a specific tissue, usually two to four reference genes are sufficient. Taken together, ribosomal protein S19 (RPS19), ribosomal protein S5 (RPS5), $\beta$-2-microglobulin (B2M), and hypoxanthine phosphoribosyltransferase (HPRT) are advocated. However, the optimal set of reference genes depends on the tissue and should be selected and evaluated for each series of experiments.
\end{abstract}

(C) 2006 Elsevier Inc. All rights reserved.

Keywords: Dog; Housekeeping; Animal model; Quantitative; PCR

The Human Genome Project and the sequencing of the complete mouse genome have revolutionized biomedical research. Furthermore, the availability of (tissue-specific) knockout mice provides an efficient tool enabling the dissection of gene functions. However, the complexity in the human clinical setting is not reflected in experimental mouse models that are uniform inbred strains. Therefore, the need to find model animals filling this gap is of utmost importance. Recently, the dog became a model organism in translational physiology to bridge rodent models to human medicine. Examples include car-

\footnotetext{
${ }^{*}$ Corresponding author. Fax: +31302518126.

E-mail address: b.brinkhof@vet.uu.nl (B. Brinkhof).
}

diovascular diseases [1], hematopoietic diseases [2,3], and copper storage diseases such as Wilson's disease [4]. In some cases, the genetic defect has been found in dogs first and in humans only later [5]. The biomedical relevance of the dog justified the complete sequencing of its genome [6]. Surprisingly, the dog genome turned out to be much more closely related to the human genome than to the mouse genome despite an earlier evolutionary split [7].

To become fully accepted as a model animal for human medicine, diseases must be similar at the clinical, pathological, and genetic levels as well as at the molecular level. Comparison at the molecular level most often relies on gene expression profiling. Furthermore, gene expression profiles can be used to gain insight into molecular pathways, distinguishing between diseased and healthy tissue as well as finding genetic mutations. Real-time quantitative 
PCR (qPCR) ${ }^{1}$ is an accurate, rapid, and sensitive technique in biological research to study differential gene expression. Several variables need to be controlled in gene expression analysis [8], including RNA integrity or input concentration of cDNA, enzymatic efficiencies, and differences between tissues or cells in overall transcriptional activity [9]. To cover for all of these variables, an internal standard is commonly used. Over the years, the technique has become more sensitive and reproducible, thereby demanding more stringent internal standards. Reference genes most frequently are used as internal standards and are selected on their supposedly equal expression in each cell of a specific tissue regardless of the individual. In human biomedical research, there are several reports on evaluating reference genes [9-11] or the qPCR technique [12-14]. To our knowledge, the evaluation of reference genes for accurate normalization of gene expression has not been done extensively for domestic animals [15-17].

In the current study, we tested nine primer sets for their potential to be used as reference genes in canine samples. The experimental design was first to optimize qPCR conditions of the different reference gene primer sets on material derived from several canine cell lines and 36 tissues samples from an 8-week-old dog. Second, analysis of these cell lines and tissues indicated the differential expression of the reference genes between various tissues. Third, the variation within specific tissue types was tested in canine prostate, kidney, mammary gland, left ventricle, and liver. Each tissue type was represented by an average of seven samples obtained from different breeds, sexes, ages, and body weights, using affected tissue as well as healthy tissue to exclude sampling bias.

\section{Materials and methods}

All procedures were approved by the Utrecht University ethical committee, as required under Dutch legislation. Samples were obtained after written consent from the owner. No experimental animals were used for the sole purpose of this study.

\section{Tissue collection}

Cell lines used were prostate-derived tissue $(\mathrm{ACE}+$, $\mathrm{CPA}+, \mathrm{CAPE}+$, and DPC), hepatic epithelial (cHCC and BDE), and kidney (MDCK), cultured under standard conditions [18-21]. Cells were washed with phosphate-buffered saline (PBS) and immediately lysed in Trizol and

\footnotetext{
${ }^{1}$ Abbreviations used: qPCR, real-time quantitative PCR; PBS, phosphate-buffered saline; $T_{\mathrm{m}}$, melting temperature; G3P, glyceraldehyde-3phosphatedehydrogenase; ACTB, $\beta$-actin; HPRT, hypoxanthine phosphoribosyltransferase; $\mathrm{B} 2 \mathrm{M}, \beta$-2-microglobulin; BGLR, $\beta$-glucuronidase; hnRNPH, heterogeneous nuclear ribonucleoprotein H; RPL8, ribosomal protein L8; RPS5, ribosomal protein S5: RPS19, ribosomal protein S19; $C_{\mathrm{t}}$, threshold cycle; 18SrRNA, $18 \mathrm{~S}$ ribosomal RNA; GUSB, $\beta-$ glucuronidase.
}

stored at $-20{ }^{\circ} \mathrm{C}$ until RNA isolation. From an 8-weekold sacrificed female Beagle dog with no clinical history, 30 fresh tissue samples were obtained and immediately snap-frozen and stored at $-70{ }^{\circ} \mathrm{C}$. Samples from prostate, kidney, mammary gland, left ventricle, and liver were obtained from necropsy tissue of an average of seven different dogs, and these samples were snap-frozen and stored at $-70{ }^{\circ} \mathrm{C}$ until RNA isolation. All samples (cell lines and tissues/biopsies) were defrosted once and immediately lysed in Trizol to minimize freeze-thawing artifacts.

\section{$R N A$ isolation and $c D N A$ synthesis}

Total RNA was extracted from tissue samples or cell line material using Trizol reagent (Invitrogen, Breda, The Netherlands) according to the manufacturer's protocol with two minor modifications. After an additional phenol/chloroform/isoamyl alcohol (125:24:1, Sigma-Aldrich Chemie, Zwijndrecht, The Netherlands) extraction was performed, the 2-propanol (Sigma-Aldrich Chemie) precipitation at $-20{ }^{\circ} \mathrm{C}$ was facilitated by adding $1 \mu \mathrm{l}(20 \mu \mathrm{g} /$ ml) glycogen (Roche, Woerden, The Netherlands). After precipitation, RNA pellets were dissolved in $30 \mu \mathrm{l}$ RNasefree TE buffer (10 mM Tris-HCl, $1 \mathrm{mM}$ EDTA, $\mathrm{pH}$ 8.0). The RNA was quantified spectrophotometrically using Nanodrop ND-1000 (Isogen Life Science, IJsselstein, The Netherlands), thereafter set to a $0.1-\mu \mathrm{g} / \mu 1$ concentration. The Agilent 2100 bioanalyzer (Agilent Technologies Netherlands, Amstelveen, The Netherlands) with a supplied Agilent standard marker was used as an independent technique to gain information about quality of the purified RNA. All measurements indicated intact and good quality RNA (data not shown). Then $1 \mu \mathrm{g}$ of each total RNA sample was used to synthesize cDNA with an MMLV-derived reverse transcriptase according to the manufacturer's protocol (iScript cDNA Synthesis Kit, Bio-Rad, Veenendaal, The Netherlands). After synthesis, the cDNA samples were diluted two times. Samples were screened for genomic contamination using qPCR. The first step was 45 cycles denaturing template for $20 \mathrm{~s}$ at $95^{\circ} \mathrm{C}$, followed by $30 \mathrm{~s}$ at melting temperature $\left(T_{\mathrm{m}}\right)$ and, for all samples, a 30-s elongation at $72{ }^{\circ} \mathrm{C}$. The second step was 5 min elongation at $72{ }^{\circ} \mathrm{C}$, followed by generating a melting curve starting at $65^{\circ} \mathrm{C}$ and increasing to $99^{\circ} \mathrm{C}$ by $1{ }^{\circ} \mathrm{C}$ each cycle for $15 \mathrm{~s}$. For this purpose, a non-reverse-transcribed RNA template as negative control, a cDNA template, and a gDNA template as a positive control were included.

\section{Primer design and testing}

The selection of candidate reference genes was based on gene targets already used as reference genes in dog and human tissues; furthermore, they represent different functional classes. The use of glyceraldehyde-3-phosphatedehydrogenase (G3P) [22], $\beta$-actin (ACTB) [19,23], and hypoxanthine phosphoribosyltransferase (HPRT) [19,22] as canine reference genes has been described previously. 
$\beta$-2-Microglobulin (B2M), $\beta$-glucuronidase (BGLR), heterogeneous nuclear ribonucleoprotein $\mathrm{H}$ (hnRNPH), ribosomal protein L8 (RPL8), ribosomal protein S5 (RPS5), and ribosomal protein S19 (RPS19) frequently are used as reference genes in murine and human research. Primer sets were developed using known dog sequences (Table 1) available from Ensembl (www.ensembl.org) or GenBank (www.ncbi.nih.gov/genbank/index.html). Primer design was performed with Oligo Explorer 1.1.0 software (www.genelink.com/tools/gl-downloads.asp). To reduce chances of amplifying traces of genomic DNA, the primers were positioned in different exons. Uniqueness and specificity of each primer were verified using the Basic Local Alignment Search Tool (www.ncbi.nlm.nih.gov/blast) returning GenBank Accession Nos. Mfold (www.bioinfo. rpi.edu/applications/mfold) was used to determine the formation of secondary structures in the formed product.

\section{Quantitative PCR}

qPCR was based on the high-affinity, double-stranded DNA-binding dye SYBR green using a Bio-Rad My-IQ detection system (IQ SYBR green Supermix and My-IQ, Bio-Rad) according to the manufacturer's instructions. Primers (Isogen Life Science) had a final concentration of $400 \mathrm{nM}$ each. For each reaction, $1 \mu \mathrm{cDNA}$ template was used. Reactions with a $T_{\mathrm{m}}$ less than $58^{\circ} \mathrm{C}$ started with $5 \mathrm{~min}$ at $95^{\circ} \mathrm{C}$, followed by 40 cycles of $20 \mathrm{~s}$ at $95^{\circ} \mathrm{C}$, $30 \mathrm{~s}$ at $T_{\mathrm{m}}$, and $30 \mathrm{~s}$ at $72^{\circ} \mathrm{C}$. This reaction was continued by $30 \mathrm{~s}$ at $60^{\circ} \mathrm{C}$, followed by a melting curve, stepwise increasing temperature each $15 \mathrm{~s}$ by $0.5^{\circ} \mathrm{C}$, ranging from 60 to $95^{\circ} \mathrm{C}$. In case the $T_{\mathrm{m}}$ was $58^{\circ} \mathrm{C}$ or higher, the elongation step at $72{ }^{\circ} \mathrm{C}$ was removed from each cycle and $T_{\mathrm{m}}$ remained $30 \mathrm{~s}$. Optimal $T_{\mathrm{m}}$ was determined using a temperature gradient ranging from 50 to $65^{\circ} \mathrm{C}$ on a 10 -fold dilution series using cDNA derived from the cell lines and from the 30 different tissues of one female Beagle dog. Analysis was performed with My-IQ software (Bio-Rad). Calculations to estimate expression stability and the pairwise var- iation were performed using geNorm (http://medgen. ugent.be/ jvdesomp/genorm) [9].

\section{Results}

\section{Optimization}

We optimized the PCR reaction for the nine potential reference genes (ACTB, G3P, HPRT, B2M, BGLR, hnRNPH, RPL8, RPS5, and RPS19). Optimal $T_{\mathrm{m}}$ values are depicted in Table 2, ranging from $55^{\circ} \mathrm{C}$ for RPL8 to $62.5^{\circ} \mathrm{C}$ for RPS5. Primer efficiency calculations $\left(E=\left(10^{-\frac{-1}{- \text { slope }}}-1\right) \times 100 \%\right)$ of all standard lines were between 96.5 and $103.9 \%$. Furthermore, all melting curves described a single distinctive peak, indicating the formation of one specific amplicon (data not shown). The specificity of the PCR reaction was confirmed by sequencing of the amplicon (data not shown). In Fig. 1, several controls are represented: (i) the presence of genomic contamination in RNA isolations and cDNA, (ii) the existence of processed pseudogenes, and (iii) the capability of the primers to amplify genomic DNA at all. In all non-reverse-transcribed reactions (except a very faint band for G3P), no product was detectable, implying no significant contribution of gDNA. Quantitative data revealed a greater than 8000 -fold lower expression in the non-reverse-transcribed samples to cDNA levels (qPCR data not shown). The presence of gDNA-derived amplicons with similar sizes as the cDNA-derived amplicons indicated the existence of processed pseudogenes, as observed for GAPDH, hnRNPH, HPRT, RPL8, RPS5, and RPS19. Although in most primer pairs one primer was intron spanning, a product was detected in most genomic DNA samples. Sizes were consistent with expected size (Table 2).

\section{Expression of reference genes in different tissues}

The cDNA from the cell lines and Beagle dog tissues were used to gain insight into the differential expression between various tissues and different cell lines. The pro-

Table 1

Reference genes used/developed and evaluated in this study

\begin{tabular}{|c|c|c|c|c|}
\hline Gene $^{\mathrm{a}}$ & GenBank Accession No. & Name & Chromosomal location in Canis familiaris & Pseudogenes \\
\hline $\mathrm{G}^{2} \mathrm{P}^{\mathrm{b}},[9,11,28,29]$ & NM_001003142 & Glyceraldehyde-3-phosphate dehydrogenase & Chromosome $\mathrm{X}$ & $+[16,30]$ \\
\hline $\mathrm{ACTB}^{\mathrm{b}},[9,11,28,29]$ & $\mathrm{XM}-536230^{\mathrm{c}}$ & $\beta$-Actin & Chromosome 6 & $+[31,32]$ \\
\hline $\mathrm{HPRT}^{\mathrm{b}},[9,11,28]$ & AY $\overline{283372}$ & Hypoxanthine phosphoribosyltransferase 1 & Chromosome X & $+[16,33]$ \\
\hline $\mathrm{B} 2 \mathrm{M}[9,11,28,29]$ & XM $535458^{\mathrm{c}}$ & $\beta$-2-Microglobulin & Chromosome 30 & - \\
\hline BGLR $[11,28]$ & NM_001003191 & $\beta$-Glucuronidase & Chromosome 6 & - \\
\hline hnRNPH[29,34] & XM_538576 ${ }^{\mathrm{c}}$ & Heterogeneous nuclear ribonucleoprotein $\mathrm{H}$ & Chromosome 11 & $+^{\mathrm{d}}$ \\
\hline RPL8[29] & $\mathrm{XM} 532360^{\mathrm{c}}$ & Ribosomal protein L8 & Chromosome 13 & - \\
\hline RPS5[29] & XM_533568 ${ }^{\mathrm{c}}$ & Ribosomal protein S5 & Chromosome 1 & - \\
\hline RPS19[29] & XM_533657 $7^{\mathrm{c}}$ & Ribosomal protein S19 & Chromosome 1 & $+{ }^{\mathrm{d}}$ \\
\hline
\end{tabular}

\footnotetext{
${ }^{a}$ References indicate evaluation in human research.

b Already in use within current authors' department.

${ }^{c}$ Predicted sequence.

d According to Ensembl (www.ensembl.org).
} 
Table 2

Primer sequences, exon locations, sizes of formed products, and optimal primer melting temperatures

\begin{tabular}{|c|c|c|c|c|c|c|}
\hline Gene & Forward $5^{\prime} \rightarrow 3^{\prime}$ & Exon(s) & Reverse $5^{\prime} \rightarrow 3^{\prime}$ & Exon(s) & Product length (bp) & $T_{\mathrm{m}}\left({ }^{\circ} \mathrm{C}\right)$ \\
\hline G3P & TGTCCCCACCCCCAATGTATC & 2 & CTCCGATGCCTGCTTCACTACCTT & 2 & 100 & 58.0 \\
\hline ACTB & GATATCGCCGCGCTCGTCGTC & 1 & GGCTGGGGTGTTGAAGGTCTC & 3 & $384^{\mathrm{a}}$ & 58.0 \\
\hline HPRT & AG/CTTGCTGGTGAAAAGGAC & $5 / 6$ & TTATAGTCAAGGGCATATCC & 7 & $114^{\mathrm{b}}$ & 56.0 \\
\hline B2M & TCCTCATCCTCCTCGCT & 1 & ТTCTCTGCTGGGTGTCG & 2 & $85^{\mathrm{c}}$ & 61.2 \\
\hline BGLR & AGACGCTTCCAA/GTACCCC & $3 / 4$ & AGGTGTGGTGTAGAGGAGCAC & 4 & 103 & 62.0 \\
\hline hnRNPH & CTCACTATGATCCACCACG & 5 & TAGCCTCCATAAC/CTCCAC & $6 / 5$ & 151 & 61.2 \\
\hline RPL8 & CCATGAAT/CCTGTGGAGC & $4 / 5$ & GTAGAGGGTTTGCCGATG & 5 & 64 & 55.0 \\
\hline RPS5 & TCACTGGTGAG/AACCCCCT & $2 / 3$ & CCTGATTCACACGGCGTAG & 3 & 141 & 62.5 \\
\hline RPS19 & ССТTCСТCAAAAA/GTCTGGG & $2 / 3$ & GTTCTCATCGTAGGGAGCAAG & 3 & 95 & 61.0 \\
\hline
\end{tabular}

Note. If a primer is located on two exons, the junctions are shown with a dividing forward slash (/).

${ }^{a}$ Genomic product size would be approximately $800 \mathrm{bp}$.

b Genomic product size would be approximately $300 \mathrm{bp}$.

${ }^{\mathrm{c}}$ Genomic product size would be $3.6 \mathrm{~kb}$.

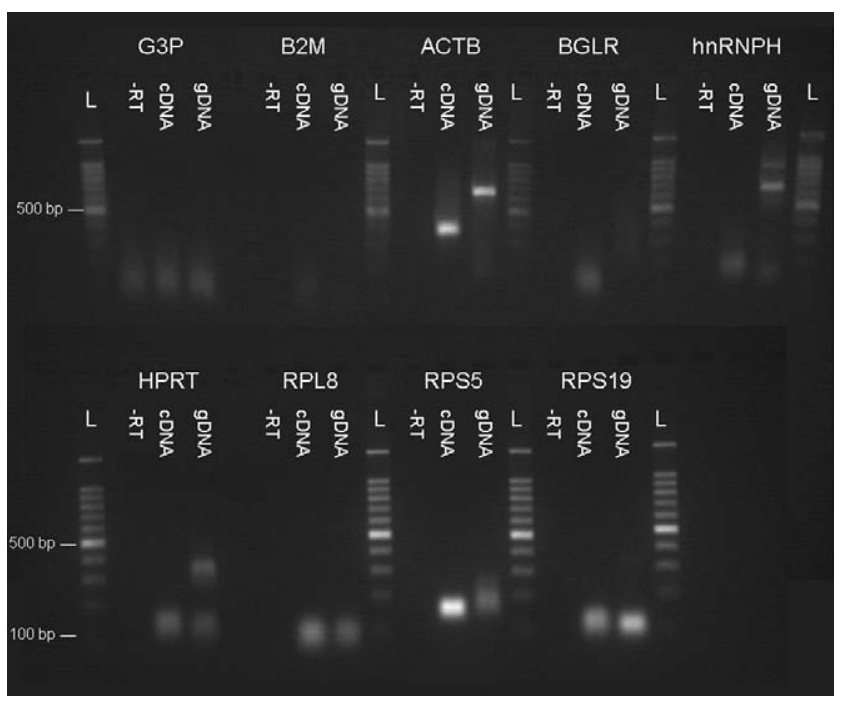

Fig. 1. Electrophoresis of qPCR results. Each potential reference gene was used to show the contribution of contaminating gDNA. This figure (based on a prostate sample) is representative of all samples used. For all samples, a non-reverse-transcribed RNA (-RT), cDNA, and gDNA sample were tested $(2 \%$ agarose in $1 \times$ TAE buffer, $70 \mathrm{~V}$ for $2.5 \mathrm{~h})$. L, size marker.

gram geNorm calculates the gene expression stability measure $M$ of one gene based on the average pairwise variation between all studied genes. The lowest $M$ values characterize genes with the most stable expression. Successive elimination of the least stable gene generates a ranking of genes according to their $M$ values and results in the identification of the two most stable genes [24]. In Table 3A, the expression stability ranking is depicted for the reference genes of all cell lines and tissues studied in the first experiment (one Beagle dog, wide range of different tissues). The top four are the same for both analyses, although the order may be different. Overall, RPS5, RPL8, RPS19, and HPRT were the most stably expressed gene products, whereas ACTB was the least stable (Table 3A). For the quantitative comparison of amplification rates of the investigated candidate reference genes, the threshold cycle $\left(C_{\mathrm{t}}\right.$ value $)$ defines the fluorescence signal point where a background fluorescence signal is exceeded. The $C_{\mathrm{t}}$ correlates inversely to the cDNA concentration and depends on PCR efficiency [24]. Although the $C_{\mathrm{t}}$ values of the nine reference genes studies cover a wide dynamic range $\left(C_{\mathrm{t}}=20-30\right)$, there is no apparent correlation between the $C_{\mathrm{t}}$ values and the $M$ values (Fig. 2). There is no correlation between product size and $M$ value for amplicons smaller than $160 \mathrm{bp}$ (Fig. 3). The highest $M$ value was found with ACTB, the only product larger than $300 \mathrm{bp}$.

\section{Individual variation}

The reference gene variation within specific tissue types was tested in prostate, kidney, mammary gland, left ventricle, and liver tissues from five to nine dogs of different breeds, sexes, ages, and body weights, using affected tissue as well as healthy tissue (Table 3B). Although the order of stability of the different gene products varied among the five tissues, RPS5 always was within the three most stable and RPS19 always was in the top four in reference gene stability. The expression of ACTB was unstable in prostate, kidney, mammary gland, and left ventricle. Because ACTB was not detected in all liver samples, it was left out of the calculations represented in Table 3B. Apart from the expression stability $(M)$ between genes, we determined the number of reference genes needed to obtain sufficiently high quality of internal controls. GeNorm calculates the normalization factor assessing the optimal number of reference genes for generating the already mentioned $M$ factor by calculating the pairwise variation $V$. This normalization factor is calculated from the expression data of at least two genes. The pairwise variation between these genes defines the variable $V$ [24]. Fig. 4 shows the influence of an increasing number of reference genes on the pairwise variation $V$. As depicted, little if any improvement was seen using more than three independent reference genes, irrespective of the tissue type.

\section{Discussion}

In view of food safety and animal welfare, in-depth studies on the validation of primers for reference genes in cattle 
Table 3

Gene ranking according to geNorm calculations

\begin{tabular}{|c|c|c|c|c|c|c|c|c|c|}
\hline & \multicolumn{3}{|c|}{ (A) Single dog (first) experiment } & \multicolumn{6}{|c|}{ (B) Intratissue variability (second) experiment } \\
\hline & Cell line & Tissue & Total & Total & Liver $^{\mathrm{a}}$ & Kidney & Left ventricle & Mammary gland & Prostate \\
\hline \multirow{9}{*}{ 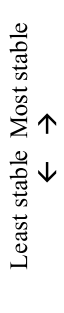 } & RPS19 & RPS5 & RPS5 & RPS5 & RPS5 & RPS5 & $\mathrm{B} 2 \mathrm{M}$ & RPS5 & RPL8 \\
\hline & HPRT & RPL8 & RPL8 & RPL8 & HPRT & RPS19 & RPS19 & RPS19 & HPRT \\
\hline & RPS5 & RPS19 & RPS19 & HPRT & $\mathrm{B} 2 \mathrm{M}$ & RPL8 & RPS5 & RPL8 & RPS5 \\
\hline & RPL8 & HPRT & HPRT & RPS19 & RPS19 & G3P & G3P & HPRT & RPS19 \\
\hline & G3P & B2M & hnRNPH & B2M & BGLR & $\mathrm{B} 2 \mathrm{M}$ & BGLR & B2M & hnRNPH \\
\hline & hnRNPH & BGLR & BGLR & hnRNPH & RPL8 & HPRT & HPRT & G3P & BGLR \\
\hline & BGLR & hnRNPH & $\mathrm{B} 2 \mathrm{M}$ & BGLR & G3P & BGLR & RPL8 & hnRNPH & G3P \\
\hline & ACTB & G3P & G3P & G3P & hnRNPH & АСТВ & hnRNPH & BGLR & $\mathrm{B} 2 \mathrm{M}$ \\
\hline & B2M & ACTB & ACTB & ACTB & & hnRNPH & $\mathrm{ACTB}$ & $\mathrm{ACTB}$ & $\mathrm{ACTB}$ \\
\hline
\end{tabular}

Note. The two most stable control genes cannot be ranked because of the required use of gene ratios for gene stability measurements.

a Because there was not enough data from ACTB, this gene is left out in the liver ranking.

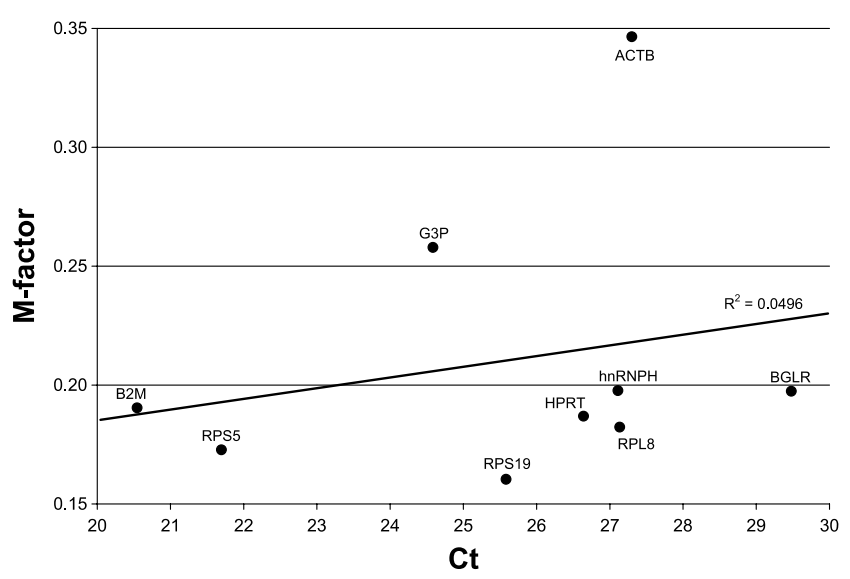

Fig. 2. Expression stability $(M)$ versus raw expression values $\left(C_{\mathrm{t}}\right)$. The lowest $M$ values characterize genes with the most stable expression. According to the diverse scatter, there was no relation $\left(R^{2}=0.0496\right)$ between expression stability and expression values.

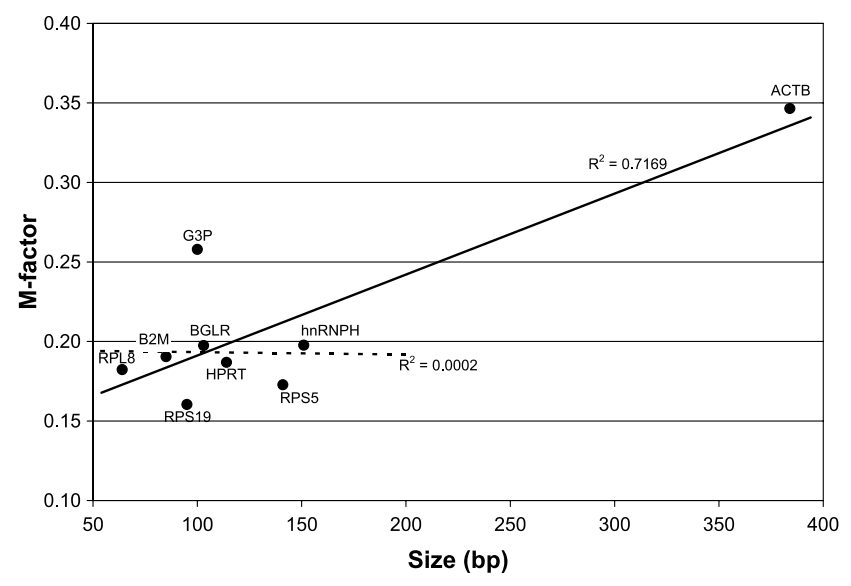

Fig. 3. Expression stability $(M)$ versus product size (bp). The size of ACTB (384 bp) might influence $\left(R^{2}=0.72\right)$ the $M$ factor (solid line). Leaving ACTB out, the small products $(64-151 \mathrm{bp})$ are not correlated $\left(R^{2}=0.00\right)$ to the $M$ factor (dashed line).

and pigs have been performed $[25,26]$. The research interest in companion animals such as dogs has been limited mainly to veterinary schools. The recent increase in use of these animals as models for human (patho)physiology has obviated the need to expand the primer validation results by Peters and coworkers [8] performed on canine samples. Therefore, we analyzed nine gene products frequently used as reference genes for their ability to be used as reference genes in canine qPCR measurements. The potential reference genes (ACTB, BGLR, RPL8, B2M, RPS19, RPS5, hnRNPH, G3P, and HPRT) were of different functionalities as well as different locations. To gain insight into tissue-tissue variations, we analyzed potential reference genes in five tissue types: prostate, mammary gland, left ventricle, kidney, and liver. Each tissue type was represented by snap-frozen samples from five to nine dogs.

A few points clearly stand out from these results. First, there is no single reference gene that is the most stable in all tissues tested. Second, the data demonstrated notable differences in the variability of reference gene stability in the chosen tissues. Third, RPS5 and RPS19 showed very stable expression levels. Fourth, ACTB was relatively unstably expressed (Table 3). Furthermore, an estimation of the lowest number of reference genes required in a specific tissue is even more critical if the amount of material (e.g., from live patients) is limited. In general, the use of two to four reference genes resulted in sufficient reliability of the internal controls (Fig. 3). The practical consequence with regard to the experimental design of differential expression profiling studies in dog tissues is that validation of reference genes for tissues not previously described in qPCR is needed.

An initial screening with RPS5 and RPS19, preferably one of each done at the start of, midway through, or at the end of the expression profiling, indicates the differential expression of the gene products of interest. However, because the geNorm algorithm is founded on the assumption that the candidate reference genes belong to different functional classes, the sole use of these two reference genes may bias the interpretation of the data. B2M and HPRT are from other functional classes and often score the highest stability. Therefore, they can be suitable alternatives or additions, although they might not be the first choice in some tissues. In addition, HPRT was also advocated above 


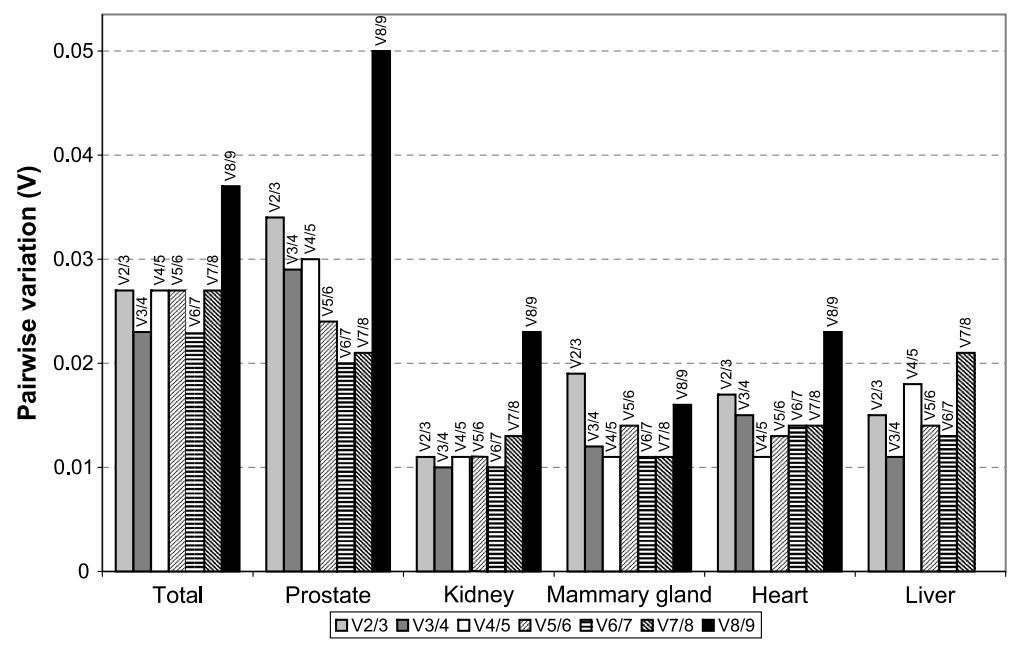

Fig. 4. Determination of the optimal number of reference genes for normalization. The geNorm software calculates the normalization factor from at least two genes of which the variable $V$ defines the pairwise variation between two sequential normalization factors. For example, $V 3 / 4$ shows the variation of the normalization factor of three genes in relation to four genes. No decline to the next comparison implies that there is no need for using more reference genes.

G3P and ACTB in cattle and pigs [25,26], especially for highly sensitive analyses such as qPCR.

It is possible that the apparent relative unstable expression of ACTB is due to the primers used, and consequently to the amplicon size, rather than a problem of ACTB per se. As shown in Fig. 3, the amplicon size of ACTB is approximately double the size of the other amplicons tested. More important is the observation by von Smolinski and coworkers [17], who found equal G3P and ACTB qPCR expression levels even in formalin-fixed and paraffin-embedded canine liver samples. This contradiction with our results can be caused by the fact that their primers resulted in an ACTB amplicon within the size range of the other reference genes tested by us. A second explanation can be the fact that their surgical specimens taken were approximately 10 -fold larger in size than the biopsies taken by our veterinarians. If indeed the amplicon size (or the primer pair used) of ACTB was detrimental to its expression stability, interpretation of former data, including ours [23], should be reserved.

We selected nine reference genes known from human and mouse research to validate in canine research. Some of these had already been used in canine research. In general, despite the relative low stability of our ACTB reference gene, all turned out to be applicable as reference genes. Limited data are available on reference genes in the other well-known companion animal, namely the cat (Felis catus). G3P [7,9,10,12], 18S ribosomal RNA (18SrRNA) [5,8], HPRT [11], $\beta$-glucuronidase (GUSB) [6], or ACTB [1,2] is used; however, these never are used in combination. Moreover, to our knowledge, a comprehensive analysis of feline reference genes has not been published. Comparison with three other domesticated animal species (cattle [25], pigs [26], and sheep [15]) revealed either HPRT $[25,26]$ or G3P [15] as superior to ACTB, basically as we have found. This suggests that, to a certain degree, reference genes are species independent.
The presence of minor gDNA contaminations can affect the interpretation of the qPCR data. First, amplification of pseudogenes potentially can affect the results [16]. Our data confirm the existence of several pseudogenes for G3P, hnRNPH, HPRT, RPL8, RPS5, and RPS19 (Fig. 1 and Table 1). Second, amplification of DNA encoding for the reference gene can disturb data analysis. This usually is precluded by the design of intron-spanning primers. Despite the intron spanning of either one of the primers for a specific reference gene (except G3P), amplification of the reference gene from gDNA occurred. Surprisingly, annealing of as little as $6 \mathrm{bp}$ (for the reverse primer for hnRNPH) appeared to be sufficient for a proper PCR. Therefore, DNase treatment is recommended with these primers and is now included in our standard operation protocols for RNA isolation and subsequent cDNA production.

The successful amplification of a single specific sequence provides information only concerning the presence of the target sequence itself and therefore might not give insight into the integrity of all target sequences of interest, let alone the complete RNA. The use of more reference genes would be a better indicator of overall integrity of an RNA sample and, nevertheless, should be regarded as the minimum requirement controlling the integrity of the RNA sample under investigation [27]. Apart from the RNA integrity, the (small) expression variability of a reference gene needs to be normalized. When selecting only one gene as a reference gene, the expression variability might not be relevant so long as expression differences measured between groups is greater than the reference gene variation. That is, a reference gene mRNA that has an error of $1 \log$ might not be ideal, but it is sufficient to measure a 2-log change in a gene of interest [14]. Hence, in accordance with previous reports $[9,11,15]$, we also recommend the use of more than one reference gene to compensate for variations in testing samples. 
In conclusion, our approach has led to an identification of a panel of reference genes fairly stably expressed throughout a variety of canine tissues. The most appropriate reference genes in dog material are RPS19, RPS5, B2M, and HPRT. The possibility to amplify several pseudogenes with the primers under the PCR conditions as described here means that DNase treatment is recommended. If this is less feasible due to technical reasons, new primers and/or more stringent PCR conditions can be tested, as was done previously [16]. Still, we stress that reference genes need to be evaluated for each specific study given that none of the reference genes described here turned out to be universally applicable.

\section{Acknowledgments}

The authors gratefully thank J. A. Lenstra for scientific criticism and A. Mayne for manuscript editing.

\section{References}

[1] M.A. Vos, J.G. Jungschleger, Transmural repolarization gradients in vivo: the flukes and falls of the endocardium, Cardiovasc. Res. 50 (2001) 423-425.

[2] K.M. Brinkhous, R.L. Reddick, M.S. Read, T.C. Nichols, D.A. Bellinger, T.R. Griggs, Von Willebrand factor and animal models: contributions to gene therapy, thrombotic thrombocytopenic purpura, and coronary artery thrombosis, Mayo Clin. Proc. 66 (1991) 733742.

[3] W. Li, K. Tanaka, A. Ihaya, Y. Fujibayashi, S. Takamatsu, K. Morioka, M. Sasaki, T. Uesaka, T. Kimura, N. Yamada, T. Tsuda, Y. Chiba, Gene therapy for chronic myocardial ischemia using platelet-derived endothelial cell growth factor in dogs, Am. J. Physiol. Heart Circ. Physiol. 288 (2005) H408-H415.

[4] T.U. Hoogenraad, J. Rothuizen, Compliance in Wilson's disease and in copper toxicosis of Bedlington terriers, Lancet 2 (1986) 170 .

[5] L. Lin, J. Faraco, R. Li, H. Kadotani, W. Rogers, X. Lin, X. Qiu, P.J. de Jong, S. Nishino, E. Mignot, The sleep disorder canine narcolepsy is caused by a mutation in the hypocretin (orexin) receptor 2 gene, Cell 98 (1999) 365-376.

[6] E.A. Ostrander, F. Galibert, D.F. Patterson, Canine genetics comes of age, Trends Genet. 16 (2000) 117-124.

[7] K. Lindblad-Toh, C.M. Wade, T.S. Mikkelsen, E.K. Karlsson, D.B. Jaffe, M. Kamal, et al., Genome sequence, comparative analysis, and haplotype structure of the domestic dog, Nature 438 (2005) 803-819.

[8] I.R. Peters, C.R. Helps, E.J. Hall, M.J. Day, Real-time RT-PCR: considerations for efficient and sensitive assay design, J. Immunol. Methods 286 (2004) 203-217.

[9] J. Vandesompele, K. De Preter, F. Pattyn, B. Poppe, N. Van Roy, A. De Paepe, F. Speleman, Accurate normalization of real-time quantitative RT-PCR data by geometric averaging of multiple internal control genes, Genome Biol. 3 (2002), research 0034.0031-0034.0011.

[10] K. Dheda, J.F. Huggett, J.S. Chang, L.U. Kim, S.A. Bustin, M.A. Johnson, G.A. Rook, A. Zumla, The implications of using an inappropriate reference gene for real-time reverse transcription PCR data normalization, Anal. Biochem. 344 (2005) 141-143.

[11] C. Tricarico, P. Pinzani, S. Bianchi, M. Paglierani, V. Distante, M. Pazzagli, S.A. Bustin, C. Orlando, Quantitative real-time reverse transcription polymerase chain reaction: normalization to rRNA or single housekeeping genes is inappropriate for human tissue biopsies, Anal. Biochem. 309 (2002) 293-300.
[12] S.A. Bustin, Quantification of mRNA using real-time reverse transcription PCR (RT-PCR): trends and problems, J. Mol. Endocrinol. 29 (2002) 23-39.

[13] S.A. Bustin, T. Nolan, Pitfalls of quantitative real-time reversetranscription polymerase chain reaction, J. Biomol. Tech. 15 (2004) $155-166$.

[14] J. Huggett, K. Dheda, S. Bustin, A. Zumla, Real-time RT-PCR normalization: strategies and considerations, Genes Immunol. 6 (2005) 279-284.

[15] D. Garcia-Crespo, R.A. Juste, A. Hurtado, Selection of ovine housekeeping genes for normalization by real-time RT-PCR: analysis of PrP gene expression and genetic susceptibility to scrapie, BMC Vet. Res. 1 (2005) 3.

[16] C.M. Johnson, S. Yang, K.S. Sellins, G.R. Frank, Selection of HPRT primers as controls for determination of mRNA expression in dogs by RT-PCR, Vet. Immunol. Immunopathol. 99 (2004) 47-51.

[17] D. von Smolinski, I. Leverkoehne, G. von Samson-Himmelstjerna, A.D. Gruber, Impact of formalin-fixation and paraffin-embedding on the ratio between mRNA copy numbers of differently expressed genes, Histochem. Cell Biol. 124 (2005) 177-188.

[18] M. Anidjar, J.M. Villette, P. Devauchelle, F. Delisle, J.P. Cotard, C. Billotey, B. Cochand-Priollet, H. Copin, M. Barnoux, S. Triballeau, J.D. Rain, J. Fiet, P. Teillac, P. Berthon, O. Cussenot, In vivo model mimicking natural history of dog prostate cancer using DPC-1, a new canine prostate carcinoma cell line, Prostate 46 (2001) $2-10$.

[19] S.Y. Boomkens, B. Spee, J. Ijzer, R. Kisjes, H.F. Egberink, T.S. van den Ingh, J. Rothuizen, L.C. Penning, The establishment and characterization of the first canine hepatocellular carcinoma cell line, which resembles human oncogenic expression patterns, Comp. Hepatol. 3 (2004) 9.

[20] H.E. Jones, C.L. Eaton, D. Barrow, C. Dutkowski, K. Griffiths, Response of cell growth and retinoic acid receptor expression to retinoic acid in neoplastic and non-neoplastic prostate cell lines, Prostate 30 (1997) 174-182.

[21] D. Oda, C.E. Savard, L. Eng, S.P. Lee, The effect of $N$-methyl- $N^{\prime}$ nitro- $N$-nitrosoguanidine (MNNG) on cultured dog pancreatic duct epithelial cells, Pancreas 12 (1996) 109-116.

[22] B. Spee, P.J. Mandigers, B. Arends, P. Bode, T.S. van den Ingh, G. Hoffmann, J. Rothuizen, L.C. Penning, Differential expression of copper-associated and oxidative stress related proteins in a new variant of copper toxicosis in Doberman pinschers, Comp. Hepatol. 4 (2005) 3.

[23] M.A. Tryfonidou, M.A. Oosterlaken-Dijksterhuis, J.A. Mol, T.S. van den Ingh, W.E. van den Brom, H.A. Hazewinkel, 24Hydroxylase: potential key regulator in hypervitaminosis D3 in growing dogs, Am. J. Physiol. Endocrinol. Metab. 284 (2003) E505-E513.

[24] F. Ohl, M. Jung, C. Xu, C. Stephan, A. Rabien, M. Burkhardt, A. Nitsche, G. Kristiansen, S.A. Loening, A. Radonic, K. Jung, Gene expression studies in prostate cancer tissue: which reference gene should be selected for normalization? J. Mol. Med. 83 (2005) 1014 1024.

[25] R. Fitzpatrick, O.M. Casey, D. Morris, T. Smith, R. Powell, J.M. Sreenan, Postmortem stability of RNA isolated from bovine reproductive tissues, Biochim. Biophys. Acta 1574 (2002) 10-14.

[26] D.L. Foss, M.J. Baarsch, M.P. Murtaugh, Regulation of hypoxanthine phosphoribosyltransferase, glyceraldehydes-3-phosphate dehydrogenase, and $\beta$-actin mRNA expression in porcine immune cells and tissues, Anim. Biotechnol. 9 (1998) 67-78.

[27] T. Lion, Current recommendations for positive controls in RT-PCR assays, Leukemia 15 (2001) 1033-1037.

[28] C. Rubie, K. Kempf, J. Hans, T. Su, B. Tilton, T. Georg, B. Brittner, B. Ludwig, M. Schilling, Housekeeping gene variability in normal and cancerous colorectal, pancreatic, esophageal, gastric and hepatic tissues, Mol. Cell Probes 19 (2005) 101-109.

[29] A. Sharma, V.K. Sharma, S. Horn-Saban, D. Lancet, S. Ramachandran, S.K. Brahmachari, Assessing natural variations 
in gene expression in humans by comparing with monozygotic twins using microarrays, Physiol. Genom. 21 (2005) 117123.

[30] P. Arcari, R. Martinelli, F. Salvatore, Human glyceraldehydes-3phosphate dehydrogenase pseudogenes: molecular evolution and a possible mechanism for amplification, Biochem. Genet. 27 (1989) 439450.

[31] B. Garbay, E. Boue-Grabot, M. Garret, Processed pseudogenes interfere with reverse transcriptase-polymerase chain reaction controls, Anal. Biochem. 237 (1996) 157-159.
[32] M. Moos, D. Gallwitz, Structure of two human $\beta$-actin-related processed genes one of which is located next to a simple repetitive sequence, EMBO J. 2 (1983) 757-761.

[33] L.N. Sellner, G.R. Turbett, The presence of a pseudogene may affect the use of HPRT as an endogenous mRNA control in RT-PCR, Mol. Cell Probes 10 (1996) 481-483.

[34] L.B. Rozeman, L. Hameetman, A.M. Cleton-Jansen, A.H. Taminiau, P.C. Hogendoorn, J.V. Bovee, Absence of IHH and retention of PTHrP signalling in enchondromas and central chondrosarcomas, J. Pathol. 205 (2005) 476-482. 